\title{
THE USE OF ELECTROMAGNETIC FIELD IN DESIGNING THE HIGH QUALITYAL-ALLOYS FOR HOT FORGING PROCESS
}

\author{
Zvonko Gulišija, Aleksandra Patarić*, Marija Mihailović \\ Institute for Technology of Nuclear and Other Mineral Raw Materials, \\ Franchet d'Esperey 86, 11000 Belgrade, Serbia
}

Received 15.10.2014

Accepted 24.11.2014

\begin{abstract}
This work presents a way to obtain the better quality of EN AW 7075 aluminum high-strength alloy by application of electromagnetic field (EMF) during the casting process. In this way, the uniform fine-grained microstructure, and hence the better mechanical properties of the alloy can be achieved. The microstructure and mechanical characterization for samples obtained with and without EMF were performed. The application of numerical simulation for hot forging process, using appropriate software, is efficient and highly useful tool for problem prediction in industrial production, reducing the time and costs in the process of development of new products. The input data of high strength Al-alloy EN AW-7075 is used for simulation because it enables the development of parts with complex dimensions and shape.

Keywords: electromagnetic field, Al-alloy, forging process, numerical simulation

\section{Introduction}

The EN AW 7075 aluminum alloy is a heat treatable very high strength alloy and its forgings have wide application in the aero and military industry. The conventional continuous casting process of this alloy causes many defects, such as: surface imperfections, grain boundary segregations, non-uniform grain size and porosity. Unfortunately, such structure cannot be completely eliminated in the following processing and heat treatment, resulting in reduced values of the mechanical properties. Recently, the application of electromagnetic field (EMF) has found a wide application in processing of aluminum castings. The uniform fine-grained microstructure, and hence the better mechanical properties of the alloy can be achieved by applying the EMF during the casting process. Electromagnetic casting process (EMC) is the technology developed by combining the magnetic hydrodynamics and casting technique, [1-2].
\end{abstract}

* Cooresponding author: Aleksandra Patarić, a.pataric@itnms.ac.rs 
The application of this process has been aimed at first for obtaining a better ingot surface, due to the reduced contact pressure at the metal/mould interface as the result of potential force acting, as a horizontal component of the Lorentz force density [3-5]. The other component of the Lorentz force density is a rotational component, resulting in a forced convection in the molten metal, enabling better flow of the melt and homogeneous bulk distribution of alloying elements [6-7]. These changed conditions of solidification, provided better and more uniform microstructure and mechanical properties of as cast ingots and forged parts and moreover enabled savings in energy and time.

In this study, the samples of EN AW 7075 aluminum alloy were obtained by EMC process and for comparison also by conventional casting process. A large number of aluminum castings can be forged, from the low to high strength alloys. The most commonly forged heat treated alloys are medium and high strength alloys. These materials are very sensitive to forging temperature changes. Low temperatures lead to incomplete recrystallization, deformed and undesirable microstructure. Large grains of inhomogeneous structure lead to poor mechanical properties of forged parts. The increased degree of deformation in different stages of forging process increases the strength of the forging. In contrast, the increase in the forging temperature and prolonged heat treatment time lead to the reduction of strength of the forging [8].

\section{Experimental}

The chemical composition of EN AW 7075 alloy is shown in Table 1.

Table 1. Chemical composition of alloy EN AW 7075

\begin{tabular}{|c|c|c|c|c|c|c|}
\hline Element & $\mathrm{Zn}$ & $\mathrm{Mg}$ & $\mathrm{Cu}$ & $\mathrm{Mn}$ & $\mathrm{Cr}$ & $\mathrm{Fe}$ \\
\hline $\begin{array}{c}\text { Content } \\
\text { (wt \%) }\end{array}$ & 5.51 & 2.29 & 1.45 & 0.13 & 0.19 & 0.14 \\
\hline
\end{tabular}

The experimental equipment consists of medium frequency induction furnace with $100 \mathrm{~kg}$ capacity. There is a drainpipe, at the bottom of the furnace, with vertical graphite crystallizer intensively water cooled. The low frequency magnetic field is placed around the crystallizer.

Ingots with diameter of $90 \mathrm{~mm}$ were obtained by vertical continuous casting. The sample of EN AW $7075 \mathrm{Al}$ alloy for forging process with dimensions $\varnothing 90 \times 216 \mathrm{~mm}$ was obtained with EMF casting process and produced by "Petar Drapšin", Mladenovac. The sample 1 was obtained without EMF, whereas the sample 2 was obtained with presence of EMF. The casting temperature was in the range of $710-720^{\circ} \mathrm{C}$ and the average casting speed was $1.5 \mathrm{~mm} / \mathrm{s}$. The frequency of electromagnetic field was $30 \mathrm{~Hz}$, because, our previous experience shows that this was the optimal frequency [9]. The current intensity was $200 \mathrm{~A}$. The microstructure of samples was examined by optical microscopy using the image analysis device Leica Q500MC, after the usual metallographic preparation and etching in Keller's reagent (revealing morphology of Al segregation-solid solution and inter-metallic phase). The mechanical properties, such as, yield point (Rp) and tensile strength (Rm), elongation at the fracture point (A) and reduction area (So), were determined using computerized mechanical testing machine Zwick Roel Z/100. The dimensions of tensile test samples were $\varnothing 8 \times 150 \mathrm{~mm}$. The 
example of EN AW 7075 Al-alloy forging as well as numerical simulation of the forging process is presented only for sample cast applying EMF process, due to its high strength and suitability for hot working. The forging process was performed in two steps: pre-compression and final forging at the electro-hydraulic press LASCO 1600. Before processing, tools must be preheated to a temperature of $250{ }^{\circ} \mathrm{C}$ in order to avoid thermal stress. The strain rate was $250 \mathrm{~mm} / \mathrm{s}$.

\section{Results and discussion}

The characteristic microstructure appearance at the cross section of samples cast under different conditions is shown in Figure 1. As it can be seen, the cellular/dendritic morphology is the result of $\mathrm{Al}$ segregation from the solid solution during the solidification process. Nevertheless, the morphology of the sample cast without the EMF effect, Figure 1a, is characterized by more defined dendritic srtucture, in comparison with distinctive cells in Figure 1b, obtained with EMF influence.

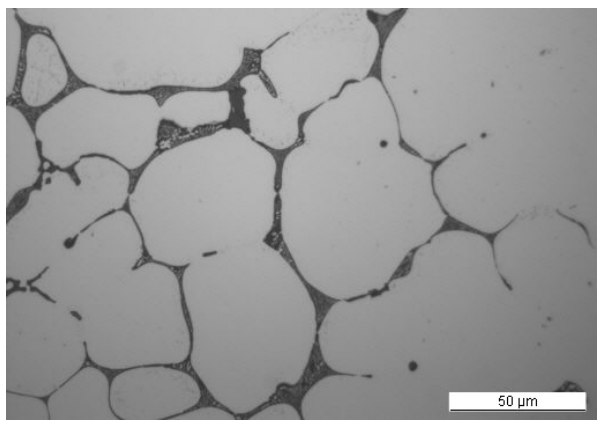

(a)

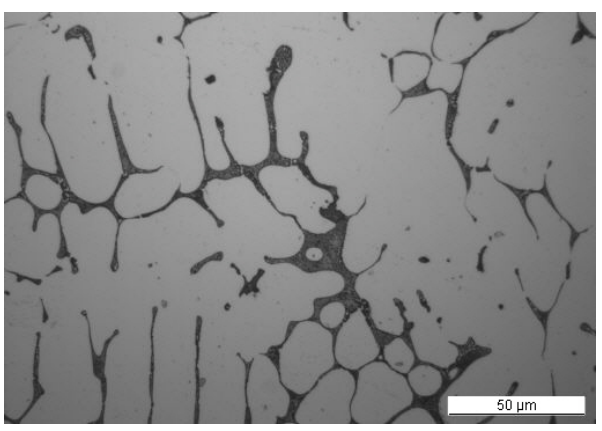

(b)

Fig. 1. Microstructure of sample cross section: sample 1 (a) and sample 2 (b), Keller's reagent, $500 x$

It was also determined that the porosity of interdendritic type was reduced in sample 2. The cross sectional microstructure of sample 2 is more homogenous then microstructure of sample 1 .

It is well known that the mechanical properties of alloy are directly related to the microstructure and its defects. The sample 2 has better mechanical properties, then sample 1, (Table 2).

Table 2 The measured mechanical properties

\begin{tabular}{|c|c|c|c|c|}
\hline Sample & $\begin{array}{c}\mathrm{Rp}, \\
\mathrm{N} / \mathrm{mm}^{2}\end{array}$ & $\begin{array}{c}\mathrm{Rm}, \\
\mathrm{N} / \mathrm{mm}^{2}\end{array}$ & $\begin{array}{c}\mathrm{A}, \\
\%\end{array}$ & $\begin{array}{c}\text { So, } \\
\mathrm{mm}^{2}\end{array}$ \\
\hline 1 & 251.53 & 362.02 & 3.81 & 50.04 \\
\hline 2 & 311.96 & 470.01 & 8.87 & 50.48 \\
\hline
\end{tabular}

The difference in flow curves for sample 1, obtained without EMF, and for sample 2, obtained with EMF is presented in Figure $2 \mathrm{a}, \mathrm{b}$. 


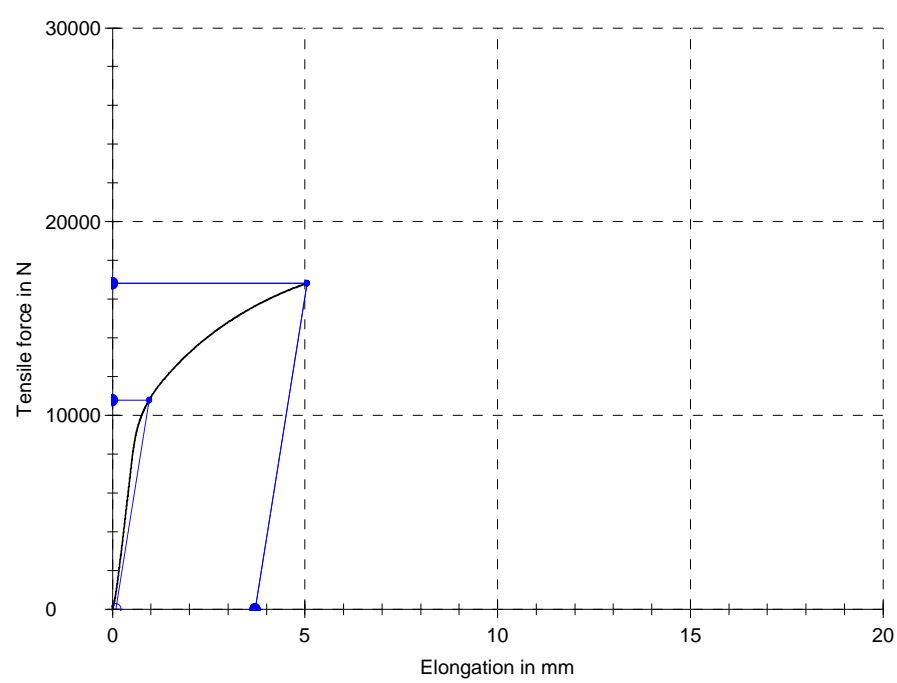

(a)

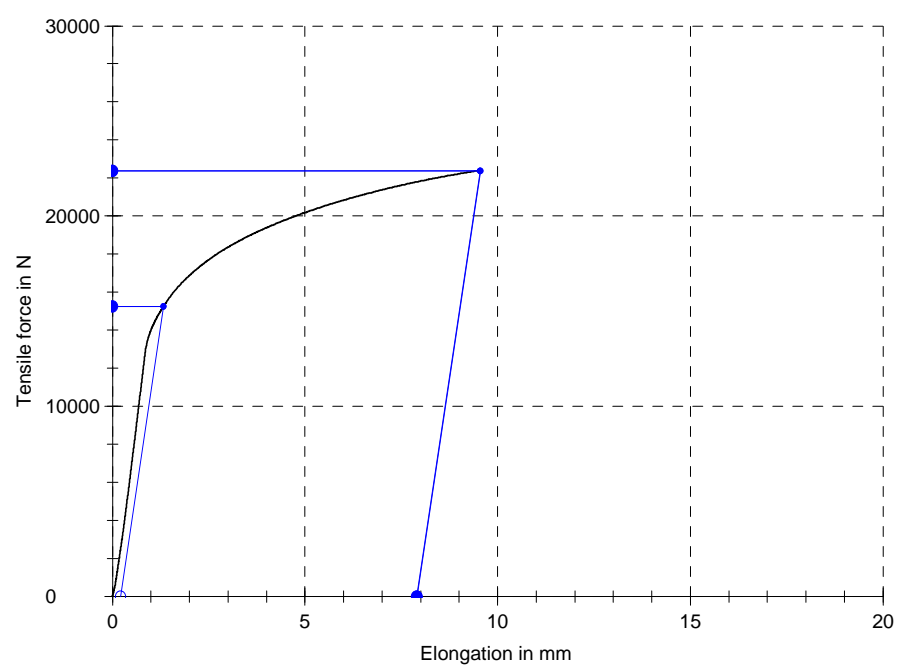

(b)

Fig. 2. Stress-elongation curves for the sample 1(a) and for the sample (2)

Temperature of forging Al-alloy depends on the type of alloy and is in the range of 320 to $480^{\circ} \mathrm{C}$ and for EN AW $7075 \mathrm{Al}$-alloy it was $405^{\circ} \mathrm{C}$. The main problem with forging Al-alloy is the need to keep the forging temperature in the strict intervals, which significantly affects the strain rate. Forging temperature intervals are narrow and must be respected.

The input data on strain hardening are important for numerical modeling [10]. In contrast to steel, the forging of Al-alloys is very sensitive to the strain rate. Numerical 
simulation of the forging process is done with well-known specialized software Simufact.Forging 11. Forgings are axially-symmetric, and the problem is solved in 2D geometry, which significantly simplifies the analysis. The results are an introduction to the analysis of forgings of much more complex configurations. Distribution of effective strain and temperature field in the cross section of forgings are shown in Figures 3 and 4 , respectively.

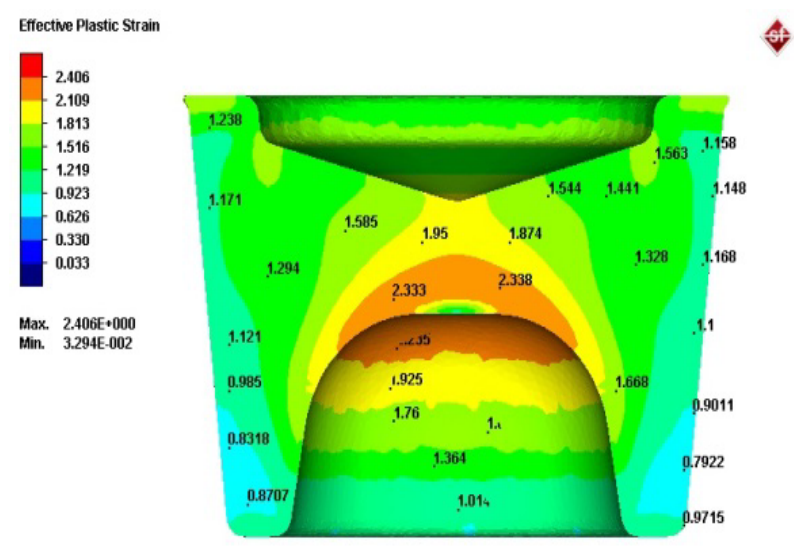

Fig.3. Distribution of effective strain

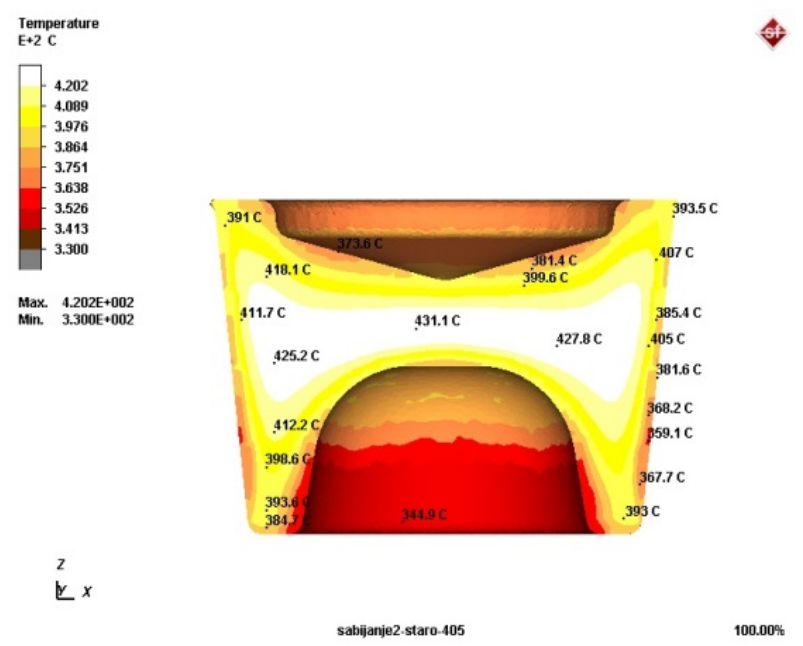

Fig. 4. Temperature field distribution

Equivalent stress reaches a maximum value of $68.95 \mathrm{MPa}$ at the end of the processing phase of forging, as shown in Figure 5. The greatest deformations are achieved in the central zone of forging, with forming deep profile. Flow within the forging leads to a rise in temperature in its centre. By choosing the optimal values of internal and external radii, flash geometry, as well as providing reliable operating 
conditions (temperature, speed, lubricant), the requirements for a reliable forging are met.

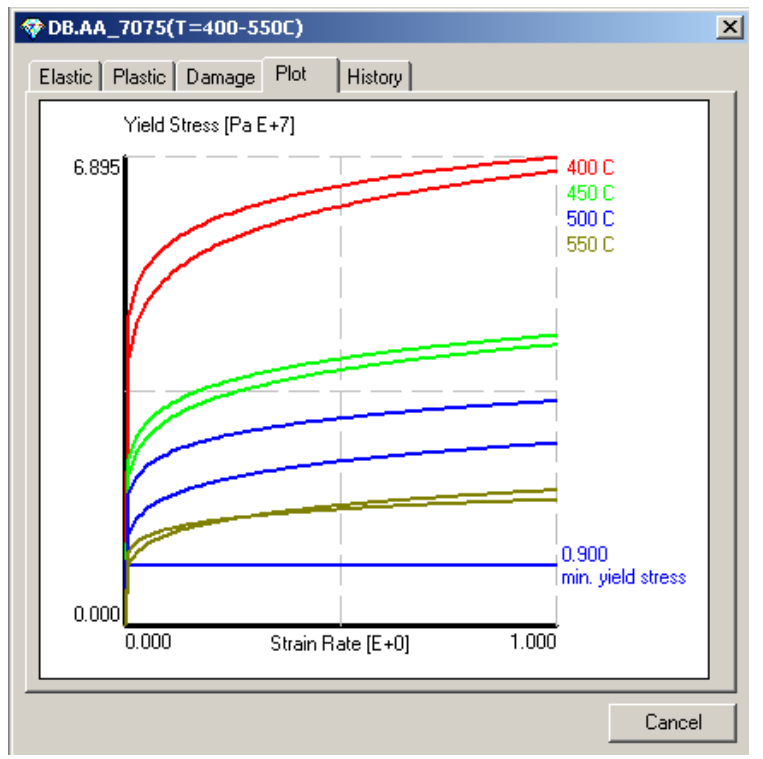

Fig. 5. Stress-strain dependence at different temperatures and strain rates for 7075Al alloy

\section{Conclusion}

During the casting without influence of electromagnetic field (EMF), due to unequal conditions of solidification, the large inhomogeneity of microstructure can be observed. The application of EMF ensures more uniform microstructure. Considering the correlation between the microstructure and mechanical properties, the sample 2 obtained with electromagnetic casting (EMC) process has higher values of mechanical properties than the sample 1, where EMF has not been applied.

By hot forging of high-strength Al-alloys, parts with high-quality structure can be obtained, with required mechanical properties only in the case when the temperature of hot forging was strictly maintained within the required interval.

Numerical analysis and application of finite elements method provide to be efficient tools for optimisation of forming process, tools construction and improvement of products quality. When developing parts of complex geometry with high requirements regarding quality, numerical tools and element of so called virtual production, are reliable and economically justified in designing of optimal technological parameters during hot forging of high-strength Al-alloys.

\section{ACKNOWLEDGEMENTS}

The authors wish to acknowledge the financial support from the Ministry of Education and Science of the Republic of Serbia through the project TR 34002. 


\section{References}

[1] Z. Zhihao, C. Jianzhong, D. Jie, J. Mater. Process. Technol. 182 (2007) 185-190

[2] Z. Zhihao, C. Jianzhong, D. Jie, W. Zhefeng W, J. Alloy. Compd. 396 (2005) 164-168

[3] Z. Beijiang, L. Guimin, C. Jianzhong, J. Mater. Sci. Technol. 18 (2002) 401-403

[4] B. Zhang, J. Cui, G. Lu, Q. Zhang, C. Ban C, Trans. Nonferrous. Met. Soc. China. 13 (2003) 158-161

[5] Q. Zhu,Y. Zhao, J. Cui, B. Zuo, .F. Qu, Acta. Metall. Sin. 21 (2008) 205-210

[6] D. Jie, C. Jianzhong, Y. Fuxiao, B. Chunyan, Z. Zhihao, Metall. Mater. Trans. 35 (2004) 2487-2494

[7] Z. Yubo, C. Jianzhong, D. Jie,Y. Fuxiao, J. Alloy. Compd. 402 (2005) 149-155

[8] V. Vazquez, T. Altan, J. Mater. Process. Technol. 98 (2000) 212-223

[9] A. Patarić, M. Mihailović, Z. Gulišija, J. Mater. Sci. 47 (2012) 793-796

[10] TALAT Lectures (2013). EAA-European Aluminium Association, www.eaa.net, accessed on 2013-03-07. 